\title{
UM ABISMO DO MESMO: SOBRE A AUTOTRADUÇÃO EM BECKETT
}

\author{
AN ABYSS OF THE SAME: ON BECKETT'S SELF-TRANSLATION
}

Ricardo Pinto de Souza

Universidade Federal do Rio de Janeiro

Rio de Janeiro, RJ, Brasil

PALAVRAS-CHAVE: tradução; Samuel Beckett; Walter Benjamin
KEYWORDS: translation; Samuel Beckett; Walter Benjamin

PALABRAS-LLAVE: traducción; Samuel Beckett; Walter Benjamin

\section{Resumo}

Este artigo trata do duplo papel de autor/tradutor que Samuel Beckett desempenhou, tomando a peça Esperando Godot como exemplo. A hipótese que se apresenta, a partir de uma leitura de $A$ tarefa do tradutor, de Walter Benjamin, é que a autotradução em Beckett se relaciona a uma espécie de reflexão e crítica sobre o niilismo ocidental. Tentaremos situar a essa hipótese na discussão de Benjamin a partir da ideia da impossibilidade de uma tradução da tradução que fosse significativa. Acreditamos que este detalhe da discussão benjaminiana sobre a tradução se refere a uma espécie de impossibilidade de escapar do caráter mítico/sagrado/absoluto da experiência humana (lembrando o peso negativo e destrutivo que o mito tem em Walter Benjamin), com o original surgindo como figuração desse sagrado, e a tradução como a figuração do caráter histórico e mutável das obras humanas.

\section{Abstract}

This paper is about the double role of Samuel Beckett as author and translator of his own work. We will take the play Waiting for Godot as an example. The hypothesis is built from an interpretation of Walter Benjamin's "The task of the translator", being that Beckett's selftranslation is related to some sort of reflexion and criticism on the Occidental niilism. We will try to situate this hypothesis in Benjamin's discussion through the conception that it is impossible to the translation of an already translated work to keep its sense. We believe that this point of Benajmin's discussion

\section{Resumen}

Este artículo trata del doble rol, autor/traductor, que desempeñó Samuel Beckett, tomando la obra Esperando a Godot como ejemplo. La hipótesis que se presenta, a partir de una lectura de La tarea del traductor, de Walter Benjamin, es que la auto-traducción en Beckett se relaciona a una especie de reflexión y crítica acerca del nihilismo occidental. Trataremos de situar a esa hipótesis en la discusión de Benjamin a partir de la idea de la imposibilidad de una traducción de la traducción que fuese significativa. Acreditamos que este detalle de la discusión benjaminiana sobre 
on translation refers to some sort of impossibility of not recognize the mythical/sacred/absolut content of the human experience (and we must have in mind the negative and destructive value that the myth has in Benjamin's work). The original would be a figuration of this sacred content, while the translated work would be the figuration of the historical and changeable aspects of human work. la traducción se refiere a una especie de imposibilidad de escapar del carácter mítico/sagrado/absoluto de la experiencia humana (recordando el peso negativo e destructivo que tiene el mito en Walter Benjamin), con el original surgiendo como figuración de ese sagrado, y la traducción como a figuración del carácter histórico y mutable de las obras humanas.

\section{ARIADNA: Hablar es hablarse Julio Cortázar, Los reyes}

Iniciemos nosso texto com uma peça de Julio Cortázar, Los reyes. ${ }^{*}$ Ela não tem relação imediata com o que vamos pensar a seguir, mas tem a virtude de propor, segundo nossa leitura, uma parábola alternativa a Babel no que se refere à relação entre decifração e alteridade. A história de Babel é conhecida: Deus, ciumento das realizações humanas, faz com que a língua primordial, una, se confunda em diversas línguas, e que a primeira nação, também una, se disperse em várias nações. $\mathrm{O}$ ato divino é misto de rivalidade (pois o homem poderia se rivalizar com o divino em sua unidade) e de justiça (a tentativa do homem de rivalizar com o divino seria uma espécie de hybris, de orgulho desmedido que teria de ser punido). De qualquer maneira, o mito de Babel, junto da expulsão de Adão e Eva, constitui a referência mitológica ao início da história, à expulsão da possibilidade de magia da condição humana. Com a expulsão do paraíso, o homem se torna temporal, limitado pela morte e pela necessidade. Com a destruição da torre, ele se vê obrigado a lidar com o múltiplo, ou seja, sua experiência gera um conhecimento imperfeito e fragmentário da realidade. Temos a história.

Babel é a narrativa privilegiada da criação da multiplicidade, e estabelece que esta é uma punição e uma marca da queda. Assim, após Babel, todo ato de decifração, cujo gesto mais radical parecenos ser a tradução, é marcado pela impossibilidade de união, pela solidão de uma identidade que não pode a partir de agora atingir algum tipo de estabilidade. Julio Cortázar tem uma alterna-

* (CORTÁZAR, Julio. Los Reyes. Buenos Aires: Suma de Letras Argentinas, 2004) 
* ENJAMIN, Walter. A tarefa do tradutor, de Walter Benjamin: quatro traduções para o português. org. Lucia Castello Branco (org.). F. Camacho; K. Barck et alii; S. K. Lages; J. Barrento (trad.). Belo Horizonte: FALE/UFMG, 2008: 83. Citamos a partir da tradução de João Barrento.) tiva para o mito da decifração. Em sua peça Los Reyes, refaz a história de Teseu e do Minotauro, mas estabelecendo uma série de diferenças em relação ao mito grego. Em primeiro lugar, Ariadne é meia-irmã do Minotauro, pois nascida da mesma mãe. Ariadne, aquela que concebe o estratagema que irá salvar Teseu do labirinto, na peça de Cortázar nutre e admite um desejo incestuoso por seu irmão impuro e bestial. Deseja se encontrar com ele e se unir, e, quando Teseu entra no labirinto, ela lhe oferece o novelo de lã, não para que o herói escape, mas para que seu irmão bestial possa sair, se liberar e se unir a ela. Não vamos produzir uma leitura extensa desta peça, mas gostaríamos de chamar a atenção para o seguinte: se a peça de Cortázar é, como desejamos, uma parábola sobre a decifração, então o decifrar em Cortázar é marcado não tanto pela aversão e pela violência, mas pelo desejo, e por um desejo que não se sente culpado pelo coito (como na imagem clássica da virgem a ser conspurcada pelo tradutor). Estamos familiarizados com as imagens eróticas relacionadas à tradução, do texto original como sendo uma virgem que deverá ser violentada pelo tradutor e que gerará o texto traduzido, este ser bestial, meio homem e meio touro, misto de duas línguas, familiarmente estranho. Cortázar nos propõe uma outra imagem: a virgem Ariadne como sendo meia-irmã deste ser monstruoso, tendo uma existência simultânea à existência do produto impuro que é o Minotauro. $\mathrm{O}$ devir de ambos é a união. Nesta chave, o ato tradutório, como qualquer ato de decifração, é, na verdade, um desejo presente já no original, a tradutibilidade do texto, como nos diz Benjamin em $A$ tarefa do tradutor. A tradutibilidade seria a exigência formal de uma determinada obra em ser traduzida, a necessidade interna de que sua forma e sentido sejam completados por uma versão em outra língua. Nas palavras de Benjamin:

A tradução é uma forma. Para a apreender enquanto tal, é necessário regressar ao original, pois nele reside a lei da tradução, contida na sua tradutibilidade (Übersetzbarkeit). A questão da possibilidade de tradução (Übersetzbarkeit) de uma obra tem um duplo sentido. Em primeiro lugar, importa saber se entre a totalidade dos seus leitores a obra encontrará um dia um tradutor à sua altura; depois, e com maior propriedade, se ela, de acordo com a sua essência, permite a tradução e assim - a condizer com a importância atribuída àquela forma - também a exige.* 
Na peça de Cortázar, o Minotauro acaba sendo morto por Teseu, não porque o herói o vença em batalha, mas por um estratagema. Teseu mente para o Minotauro e lhe diz que o novelo é um presente de Ariadne para ele, Teseu, e não para o Minotauro. Diante da suposição de que Ariadne não o deseja, o Minotauro desiste da luta e se oferece para ser morto sem resistência. A essa desistência do Minotauro quando se vê condenado a permanecer em seu isolamento, quando tem vetado seu desejo de encontro com sua outra, com o outro que lhe daria a liberdade, podemos chamar de niilismo.

Obviamente, o mito de Cortázar não se sobrepõe ao mito de Babel, não tem nem seu alcance nem sua permanência. Mas serve aqui para marcar um ponto de fuga, quando o gesto tradutório se afasta do encarceramento do sagrado. Temos aqui uma dessacralização do mito da decifração: em Babel, a multiplicidade e as ferramentas que temos para dar conta dela são marcadas como uma punição justa, provavelmente, dando a entender que o sentido da tradução é retornar ao momento de antes de Babel, quando o múltiplo era uno. O mito de Cortázar nos propõe outra conclusão: a condenação à multiplicidade não é marcada por uma culpabilidade, nem o destino do múltiplo é propriamente a unidade, mas é antes a fuga do labirinto, a possibilidade de cópula entre o monstruoso e o não monstruoso. O que impede essa cópula não é um decreto divino, mas a desistência do Minotauro. A aceitação de sua solidão, de seu horizonte murado, sua perda de vontade de liberdade, finalmente, seu niilismo, é o que o condena. O que vamos tentar fazer com nosso comentário é refletir sobre esse niilismo. A pergunta que vai estruturar este texto é a seguinte: existe algum lugar em que o Minotauro possa existir que não seja o labirinto? $\mathrm{Ou}$, colocando de outra maneira: seu desejo por uma existência para além do labirinto, para além de seu encarceramento solitário, é um desejo que tem um devir ou é um beco sem saída, um caminho que não leva a parte alguma? Apresentando a questão de uma terceira e última maneira: o niilismo de quem vive dentro do labirinto possui alguma produtividade, ele supõe um momento para além de si, uma retribuição, um dom recebido e ofertado como o novelo salvador? Há a possibilidade deste novelo decifratório, a tradução possui esta potência? Não responderemos a esta pergunta, ela não é respondível, mas merece ser pensada pela enésima vez, ao menos como exercício. 
A seguir, vamos tentar entender o trabalho de autotradução de Samuel Beckett dentro de um projeto ou de uma tarefa intelectual da modernidade que se separa em dois momentos, um antes e um após Auschwitz. O ponto de ruptura deste projeto moderno, Auschwitz, é o momento de inflexão que determina, por exemplo, a diferença de leitura entre uma teoria da tradução que ainda conta com uma certa positividade do ato intelectual, ou seja, a constelação de criação, crítica e tradução como gestos que podem ainda se diferenciar do e combater contra o niilismo, e uma teoria após Auschwitz que é obrigada a considerar na equação não apenas a superação do niilismo, mas a necessidade do niilismo, ou seja, da paralisia sufocante do mesmo, da não mudança, da indiferenciação, como um momento necessário à sua superação. Não se trata de supor que o projeto da modernidade abdique do negativo em algum momento como um elemento estrutural de sua reflexão, ao contrário, o trabalho do negativo, obrigado pela suposição póskantiana de que a condição humana não dá acesso à origem e à totalidade, é o trabalho da modernidade. A inflexão, a mudança de tom, digamos, se refere à maneira com que o trabalho do negativo é concebido. Se antes das experiências de aniquilamento da guerra se poderia conceber a crítica como a ferramenta mais perfeita de resistência ao encarceramento no mesmo, após a guerra este projeto se vê obrigado a admitir que esse encarceramento é um momento necessário para que se possa superá-lo, ou seja, que, primeiro, a representação e afirmação do niilismo são o caminho que pode garantir sua superação e que, segundo, esse além do niilismo, essa liberação do mesmo, não será jamais plena: liberar-se do niilismo através do niilismo significa essencialmente a aporia de que essa liberdade deverá ter sempre em seu horizonte a possibilidade de retornar em uma queda ao indistinto, e, mais que isso, não existe a possibilidade de evitar essa queda, ela é constantemente necessária para o surgimento de uma alteridade. Digamos, então, que o projeto da modernidade até 1945 poderia propor uma alternativa ao existente que não passasse pela reprodução do teor do existente, pela reprodução da reprodutibilidade, ou pela permanência do mesmo. $\mathrm{O}$ outro é a meta, e o outro se imagina possível, esteja ele na África, no inconsciente ou em um urinol. De qualquer maneira, o caminho crítico não é vetado, e através das formas de crítica seria possível criar um espaço de alteridade. Após 1945, essa possibilidade está interditada, e o projeto moderno é obrigado a reproduzir em 
algum nível o mesmo, o aniquilamento do mesmo, como uma ferramenta de abertura ao outro. Isto quer dizer que todo esforço crítico passa a ser marcado por uma espécie de veneno, como se destinado a fracassar de partida. Se o fracasso na primeira modernidade se identificava com a impossibilidade de estabelecer uma alteridade plena, um totalmente outro a partir dos vários pequenos outros, fragmentários, que surgem do trabalho do negativo, na modernidade após Auschwitz já não se trata da possibilidade de se tocar neste radicalmente outro, mas sim de como fazer surgir algum outro, qualquer outro, a partir do lugar niilista, a partir do mesmo. Nesse sentido, o trabalho da segunda modernidade é a tentativa de um cadáver de retornar a vida, a tentativa melancólica de se retornar a um momento anterior que, no entanto, se reconhece, já não é mais possível.

A nossa leitura do lugar da autotradução na obra de Beckett irá se referir à obra de Walter Benjamin constantemente, e isso por dois motivos. Primeiro, porque a obra de Benjamin é ao mesmo tempo a realização mais rigorosa e fértil dessa primeira modernidade e o ponto em que se começa a perceber uma espécie de inevitabilidade do niilismo. É uma obra de transição, portanto, que faz o comentário contemporâneo da possibilidade final do primeiro projeto e anuncia, ainda que timidamente, o segundo projeto. Segundo, porque a teoria da tradução de Benjamin, conforme podemos encontrar em "A tarefa do tradutor"* e em "Sobre a linguagem em geral e sobre a linguagem do homem”, * é a teoria canônica e inevitável do gesto tradutório.

Dentro da reflexão sobre a tradução, é Walter Benjamin que deixará o legado mais significativo para o nosso tempo. Sua posição privilegiada na teoria da tradução se dá, talvez, devido a sua proximidade com nosso próprio tempo. Talvez sua posição de articulação, sua voz que está em dois tempos simultaneamente, sendo dos últimos representantes fortes da tradição de pensamento que vem desde o romantismo e ao mesmo tempo trabalhando dentro dos limites e aporias que passamos a identificar com a nossa própria modernidade, seja o que lhe dê a primazia e a centralidade de que goza. Não realizaremos aqui uma exposição longa de sua teoria da tradução conforme presente em seus ensaios de juventude "A tarefa do tradutor" e "Sobre a língua em geral e sobre a língua do homem". Nosso comentário vai ser no sentido de tentar caracterizar o lugar da tradução no trabalho intelectual dentro da obra de
* (BENJAMIN, Walter, op. cit.)

* (BENJAMIN, Walter. "Sobre a linguagem em geral e sobre a linguagem do homem". trad. S. K. Lages. In: Escritos sobre mito e linguagem (1915-1921). E. Chaves; S. K. Lages (trad.). São Paulo: Duas Cidades; Ed. 34, 2011: 49-73.) 
Benjamin e relacionar seu trabalho com a prática poética e tradutória de Samuel Beckett. Primeiro, gostaríamos de localizar a função ou o significado que o gesto tradutório tem dentro da obra de Benjamin. A tradução seria um dos trabalhos específicos de crítica que Benjamin identifica com o trabalho do intelectual na modernidade. Tradução, crítica literária, crítica política e criação poética se confundem como tarefas similares em termos de dignidade e de centralidade para o intelectual moderno, não sendo possível subordinar um gesto a outro. Os quatro campos têm em comum o fato de serem processos hermenêuticos e críticos, ou seja, expressões que supõem um processo de semiose e de decifração, através da interpretação, e um processo de intervenção no real, como se através da crítica as forças subterrâneas que fluem por baixo dos destroços que a história produz pudessem ser trazidas à superfície. Essas disciplinas supõem tanto uma teoria da linguagem quanto uma teoria da história, que a princípio Benjamin deu conta de realizar na sua prática intelectual. $\mathrm{O}$ que une as duas teorias é a suposição que existe um lugar teológico, o lugar da permanência do mesmo e do absoluto, a ser combatido pelo trabalho da modernidade. O trabalho crítico se dá no sentido, então, de combater o mito e o sagrado, de impedir sua opressão e ressurgência, até o ponto em que seja possível um tempo plenamente histórico, um tempo em que este fundo teológico exista apenas de maneira frágil, como, conforme podemos encontrar em Kant, uma espécie de adorno lógico e epistemológico, e não como uma possibilidade real, como opressão provocada pelo absoluto e o silêncio.

Faremos um comentário breve acerca da maneira como entendemos a teoria da tradução de Benjamin e em seguida tentaremos localizar o trabalho de tradução de Beckett como uma prática que concorda com certas afirmações de Benjamin, especialmente que o sentido de uma obra se completa na sua tradução, mas que se afasta de sua teoria em um ponto central, também relacionado a essa conjugalidade metonímica entre original e tradução: a ideia de que a tradução seria uma estratégia, junto da crítica e da própria criação poética, que permitiria a manutenção da vida da língua, que permitiria que aquilo que ele chama a língua pura possa ser tangenciado. Para utilizar a imagem de Benjamin, a conjugalidade dos cacos das línguas do vaso arquetípico seria aquilo que permitiria a atualização permanente da vida da obra. É o fato de que uma língua não está nunca pronta em si mesma, pois é fragmento desta língua de 
sentido zero que seria a língua pura, que faz com que ela busque a tradução, é o que produz sua tradutibilidade. A figura central da teoria da tradução de Benjamin é a da língua, do teor, ou da matéria poética, ou da língua pura, como um vaso que estaria quebrado de saída. A tradução permitiria que os vários fragmentos deste vaso fossem contínua e sucessivamente encaixados, não para reconstituir este vaso, que não seria reconstituível no universo pós-kantiano e newtoniano, mas seu desejo de unidade, seu desejo de chegar à forma pura, estabeleceria um motor para se escapar do niilismo. A tarefa infinita nunca é cumprida, mas é sua necessidade lógica que permite que se escape do abismo da falta total de direção para as ações humanas. Ainda que o vaso jamais possa ser refeito, é necessário que tenha existido. Essa necessidade permite que através de um conjunto infinitamente longo de operaçôes sua imagem seja refeita. Embora cada versão de uma obra seja o atestado de um fracasso, pois os cacos das línguas, embora se unam, pareçam sempre exigir um esforço a mais para que remontem à imagem do vaso, a tradução é necessária. É o gesto decifratório que permite que a ação humana continue. Mas, para que este gesto decifratório seja possível, é necessário também que ele parta do desejo do original, seja ele o original literário, seja o original dos originais, a palavra divina. Em um universo em que o veto kantiano ao conhecimento do divino se radicaliza em um abismar-se, quando esta lógica das lógicas suposta no teor poético se torna um ponto cego e já não pode ser identificada como uma razão legítima para a decifração, entramos no niilismo. Benjamin, quando se refere a um modelo arquetípico que na crítica seria o teor da vida tornado linguagem, o poetizado, e na tradução seria a língua pura, supõe também que esse arquétipo, esse lugar vazio e indistinto onde o sagrado se cumpre não é acessível pela experiência humana. Esse é o veto kantiano ao conhecimento. Há duas respostas possíveis para esse veto: uma é a do próprio Kant, que a princípio é a posição de Benjamin também, que o veto ao absoluto exige do homem histórico um trabalho de decifração que nunca termina, sempre buscando esse absoluto, mas nunca o cumprindo, obtendo felicidade de sua própria busca, de sua ação histórica interminável. O fundo teológico tem aí uma função de um centro vazio que organiza ação, nunca de uma positividade, de um lugar a que se possa ou que se deva de fato chegar. A segunda resposta ao veto kantiano parte de uma leitura da obra de Hegel que supõe possível, através da ação histórica, chegar-se a 
uma superação total da história, a um absoluto palpável, ao fim da história. No universo de influência kantiana, a ação humana sempre se aproxima desse indistinto sagrado, mas nunca o realiza, nunca chega ao silenciamento completo que esse sagrado supóe. Seguindo uma leitura de Adorno e contemporaneamente de Agamben, temos a ruptura entre esse limite que Benjamin e a primeira modernidade imaginam válido e uma segunda modernidade, quando esse limite é ultrapassado, no evento Auschwitz. É no campo de concentração que o silenciamento total, que a completa indistinção, que a transformação do humano em um radicalmente outro são atingidos. Isso esgarça o campo do simbólico e renega da maneira mais terrível o limite kantiano ao conhecimento: após Auschwitz, o silêncio divino é conhecido, ainda que não propriamente cognoscível, e a palavra pura, que é vazia, é atingida, ainda que ela nunca pudesse ser dita. A partir de Auschwitz, temos uma cultura que é obrigada a lidar com a negatividade pura. O problema é que, conforme podemos compreender perfeitamente da altura da história em que estamos, o cumprimento do sagrado não é nem o fim da história, nem a realização de uma humanidade libertada. Continuamos a viver na história após Auschwitz, apesar de Auschwitz. Este é também o tempo em que a tarefa de tradução se complica, porque já não há mais nada a ser dito. Este é o ponto da ascensão de Beckett, da importância de sua obra, e da obrigação de se pensar uma superação do niilismo de dentro do niilismo, uma superação do silêncio quando o silêncio da língua pura foi cumprido.

Quando Beckett realiza a tradução de praticamente toda sua obra do inglês para o francês e vice-versa, ele confirma Benjamin, pois oferece uma oscilação de sentido daquilo que é dito em suas peças e romances e nos obriga a pensar em um terceiro lugar a que ambas as línguas se referem, e, de maneira bastante própria, confirma a identidade entre tradução e criação poética. Vejamos um exemplo disso em dois pequenos fragmentos de Esperando Godot. Em primeiro lugar, no caso da obra de Beckett é difícil se referir a um original e a uma tradução. Em Godot, por exemplo, a primeira versão do texto é em francês, a segunda, que seria sua tradução, é em inglês. Não vale a pena nesta circunstância nos referirmos a alguma questão cognitiva, se, por exemplo, Beckett, no caso de Godot, pensou em inglês, sua língua nativa, e realizou a escritura da peça em francês ou se pensou imediatamente em francês. A questão é que o critério de antecedência, no caso de Beckett, não serve de argu- 
mento para estabelecer um original e uma tradução. Inglês e francês são suas duas línguas de escrita, e, se o original literário de um modo supõe imediatamente sua tradução, isso é verdade em um grau enervante em uma obra que se autotraduz. Melhor dizermos, então, que ambas as versões são praticamente simultâneas, que, mais que original e tradução, temos duas versões em paralelo de uma mesma linguagem. Tomemos como exemplo as linhas abaixo:

Francês:

VLADIMIR: Ils étaient là tous les quatre. Et un seul parle d'un larron de sauvé. Pourquoi le croire plutôt que les autres?

ESTRAGON: Qui le croit?

VLADIMIR: Mais tout le monde. On ne connaît que cette versionlà.

\section{ESTRAGON: Les gens sont des cons.*}

Inglês:

VLADIMIR: But all four were there. And only one speaks of a thief being saved. Why believe him rather than the others?

ESTRAGON: Who believes him?

VLADIMIR: Everybody. It's the only version they know.

ESTRAGON: People are bloody ignorant apes.*

Português:

VLADIMIR: Todos quatro estavam lá. E só um fala em ladrão salvo. Por que acreditar nele e não nos outros?

ESTRAGON: Quem acredita nele?

VLADIMIR: Todo mundo. Foi a versão que vingou.

ESTRAGON: O povo é de uma burrice.*

A linha "O povo é de uma burrice" existe em francês como "Le gens sont de cons" e em inglês como "People are bloody ignorant apes". Se o "con, connard" do francês supõe algum grau de animalidade, indicando tanto a estupidez quanto o conho, estamos ainda longe do "bloody ignorant apes" do inglês, imagem mais concreta e mais intensa da "imbecilidade" que o francês aponta. Por outro lado, a vulgaridade malcriada e irada de "bloody ignorant apes" tem seu sentido ampliado por "cons", torna-se mais neutra, menos explosiva pela forma mais sintética. Devemos lembrar que tanto "cons" quanto "bloody ignorant apes" se referem nessa passagem do texto a uma questão teológica, à fé das pessoas na salvação do ladrão Dimas e, por metonímia, à fé na própria possibilidade de salvação, sendo ambas expressões de iconoclastia. $\mathrm{Na}$ versão
* (BECKETT, Samuel. En attendant Godot. Paris: Les éditions de minuit, 1952: 16. Grifo nosso.)

* (BECKETT, Samuel. Waiting for Godot: a tragicomedy in two acts. New York: Grove Press, 1954: 7. Grifo nosso.)

* (BECKETT, Samuel. Esperando Godot. Fábio de Souza Andrade (trad.). São Paulo: Cosac Naify, 2005: 28. Grifo nosso.) 
* (BECKETT, Samuel. Waiting for Godot: a tragicomedy in two acts. New York: Grove Press, 1954: 13. Grifos nossos.) inglesa, estabelece-se uma espécie de equalização de Estragon em relação a seu julgamento dos outros, já que não há muita diferença de nível entre quem diz "ignorant apes", que é comicamente excessivo, e aqueles a que a expressão se dirige, o que atenua esse julgamento e o torna ambíguo. Já o "cons" do francês, por ser mais sintético, estabelece a distância - e, portanto, a seriedade do julgamento - entre Estragon e aqueles a que se refere. A diferença sutil do teor do julgamento de Estragon é a distância entre desespero e leveza, entre tragédia e comédia. As duas possibilidades de semiose são contíguas, como dois polos magnéticos que se atraem, e onde uma se esgota se inicia o domínio da outra, embora o sentido final seja indecidível. É essa indecidibilidade que garante a possibilidade de tradução e na verdade estabelece sua necessidade, pois apenas na tradução esse significado contíguo, que é necessário ao sentido do julgamento de Estragon, pode surgir. Essa iluminação mútua talvez seja a relação entre os fragmentos da língua que o gesto tradutório poria em relação na imagem utilizada por Benjamin. Vejamos um segundo exemplo:

Inglês:

VLADIMIR: I don't understand.

ESTRAGON: Use your intelligence, can't you?

Vladimir uses his intelligence.

VLADIMIR: (finally) I remain in the dark.

ESTRAGON: This is how it is. (He reflects.) The bough . . . the bough ... (Angrily) Use your head, can't you?

VLADIMIR: You're my only hope.

ESTRAGON: (with effort) Gogo light - bough not break - Gogo dead. Didi heavy - bough

break - Didi alone. Whereas -

VLADIMIR: I hadn't thought of that.*

Francês:

VLADIMIR: Je ne comprends pas.

ESTRAGON: Mais réfléchis un peu, voyons.

(Vladimir réfléchit).

VLADIMIR: (finalement) Je ne comprends pas.

ESTRAGON: Je vais t'expliquer. (Il réfléchit.) La branche ... la branche ... (Avec colère) Mais essaie donc de comprendre!

VLADIMIR: Je ne compte plus que sur toi.

ESTRAGON: (avec effort). - Gogo léger - branche pas casser - Gogo mort. Didi lourd -

branche casser - Didi seul. (Un temps.) Tandis que ... (Il cherche l'expression juste.) 
VLADIMIR: Je n'avais pas pensé à ça.*

Português:

VLADIMIR: Não entendo.

ESTRAGON: Pense um pouco, use a cabeça;

(Vladimir reflete)

VLADIMIR: (finalmente) Não entendo.

ESTRAGON: Vou explicar. (Pensa) O galho... o galho... (colérico)

Tente entender!

VLADIMIR: Você é minha última esperança.

ESTRAGON: (com esforço) Gogô leve, galho não quebra, Gogô morto. Didi pesado, galho quebra, Didi sozinho. (Pausa) Enquanto que... (Busca a palavra certa)

VLADIMIR: Não tinha pensado nisto.*

O segundo exemplo nos dá os pares "I remain in the dark./ Je ne comprends pas e You're my only hopel Je ne compte plus que sur toi". As linhas se referem ao momento em que Vladimir e Estragon planejam o próprio suicídio. De novo, temos o jogo entre uma leitura mais séria e mais jocosa da afirmação dos personagens, pois "I remain in the dark" e "You're my only hope" são expressóes que têm uma ressonância escatológica bastante clara, enquanto seus correlatos em francês estão no nível da comunicabilidade mais direta. A versão em inglês reforça o terror de duas pessoas proporem a sério se suicidar, a em francês chama a atenção para a comicidade da falha de comunicação, o que cria o ridículo, pois esta falha de comunicação se dá numa conversa sobre suicídio. Como no exemplo anterior, temos a inflexão entre dois significados que se conjugam para dar acesso a uma terceira dimensão, que as inclui como parte contíguas de um dizer que nenhuma das duas dá conta em separado. E, no entanto, a única maneira de dizer esse significado indizível é através de línguas históricas que são limitadas. Logo, a tradução é necessária. $\mathrm{O}$ processo hermenêutico que produzimos aqui sobre esses exemplos poderia ser, a princípio, reproduzido em relação a qualquer outra tradução de qualquer texto forte, em que esse dizer estivesse em jogo. Mas com uma diferença essencial: neste caso não podemos falar em original e tradução senão de maneira frágil e inadequada. A autotradução de Beckett quiçá confirma a identidade entre ato criador e gesto tradutório conforme teorizado por Benjamin, a ideia de que o devir de uma obra está em sua tradução, e isso de uma maneira bastante direta, já que autor e tradutor se confundem. Mas a simultaneidade de versóes aponta para um problema
* (BECKETT, Samuel. En attendant Godot. Paris: Les éditions de minuit, 1952: 22. Grifos nossos.)

* (BECKETT, Samuel. Esperando Godot. Fábio de Souza Andrade (trad.). São Paulo: Cosac Naify, 2005: 38.) 
* (BENJAMIN, Walter. A tarefa do tradutor, de Walter Benjamin: quatro traduções para o português, op. cit.: 97.$)$ na teoria de Benjamin, qual seja, a sua afirmação de que uma tradução não pode ser ela própria traduzida, pois neste caso ambas são originais, e ambas traduções. Quando Benjamin se refere à impossibilidade da tradução de uma tradução, a princípio isso diz respeito a uma determinada lógica dentro da economia de sentido que ele estabelece em A tarefa do tradutor. Segundo Benjamin:

Quanto mais elevada for a forma de uma obra, tanto mais ela será traduzível, ainda que a tradução aflore apenas ao de leve o seu sentido. Isto aplica-se, evidentemente, apenas aos originais. As traduções, pelo contrário, revelam ser intraduzíveis, não pelo peso do sentido, mas pela enorme leveza que ele nelas assume.*

A referência da tradução não seria o sentido da obra original, mas sim a língua pura que esta não dá conta de acessar individualmente. A tradução, então, tocaria apenas de forma tangente esse sentido. Em uma tradução da tradução, esse sentido que já é exíguo desapareceria completamente e se confundiria com o texto sagrado, o que vale dizer, o texto morto, o texto sobre o qual o homem histórico já não pode agir. $\mathrm{O}$ texto sagrado é ele já tradução da tradução: o original da Vulgata, a Bíblia latina, não é a Bíblia hebraica, mas antes a palavra de Deus, e mesmo a Bíblia hebraica é a tradução de uma primeira versão perdida, e assim infinitamente até chegarmos ao escriba que ouviu a voz de Deus. O original, de qualquer forma, já não é mais acessível, o que esvazia o sentido da Escritura, faz com que ela não seja mais parte da história. Essa fuga da história, esse esvaziamento de sentido que é o motor da ação humana, é exatamente o que a proposição de Kant por uma tarefa infinita do pensamento, com que a obra de Benjamin se identifica e se propóe também como tarefa, tenta evitar. O problema é que o momento histórico do pós-guerra, o momento em que o niilismo acontece, o momento de Beckett, é aquele em que vivemos.

Quando Beckett realiza a tradução de sua própria obra, estabelece um esgotamento de possibilidade da tradução no inglês e no francês. De fato, não há uma outra versão do inglês para En attendant Godot que não seja aquela que Beckett realizou, nem uma versão do francês para Malone dies que não seja a do autor, como, de resto, de nenhum dos textos que Beckett traduziu, que são todos que produziu com exceção de um romance, uma peça de juventude e um texto de sua velhice. ${ }^{1}$ Esse silêncio venenoso, essa impossibi-

${ }^{1}$ Obviamente, não há um veto invisível ao ato de traduzir, e, de fato, há tra- 
lidade de traduzir pode perfeitamente ser acidental e motivada por razões práticas ou de ciúmes autorais. E, obviamente, a impossibilidade de se traduzir Beckett se dá apenas no inglês e no francês, e não nas centenas de outras línguas em que sua obra é encenada. Mas há concretamente essa impossibilidade de tradução. Vamos defender que existe coerência aqui em relação ao projeto artístico de Beckett. O veto à tradução estabelecido por Beckett no seio das duas principais línguas de cultura só pode ser superado radicalmente: Beckett só pode ser traduzido para o francês quando também Montaigne ou Baudelaire puderem ser, e para o inglês quando Shakespeare ou Faulkner o forem. Mas isso seria análogo à tradução da tradução que Benjamin estabelece como uma impossibilidade, pois provocaria o esvaziamento completo de sentido. Isso tornaria a tradução uma espécie de crítica literária radical, com o risco de queda num abismo de silêncio. O problema de superação do niilismo passa, em grande parte, nos parece, pela possibilidade desta tradução da tradução que não gere um silêncio. Para que esse tipo de tradução seja possível, precisaríamos de um outro mundo, que pudesse superar o niilismo a ponto de se permitir a dessacralização do texto sagrado, ou seja, do texto da grande obra, e aqui chegamos à resposta da filosofia contemporânea ao problema que Beckett se pôs. Não podemos concordar plenamente com essa resposta, ela tem alguma coisa de fácil demais, especialmente tendo como ponto de comparação a obra do próprio Beckett. Nele temos a afirmação de que esse gesto ainda não é possível, que é necessário a saída da modernidade para um outro tempo e uma outra história para que este gesto seja de fato possível. O veto à tradução, então, é a confirmação da impossibilidade de distinção, é a confirmação do silêncio niilista que cerca a modernidade. Quando esse silêncio for superado, a tradução será possível e a obra de Beckett poderá ser liberada desse caminho do labirinto em que ele próprio a confinou, talvez como uma espécie de desafio aos pósteros.

duções experimentais das obras de Beckett. A questão é que essas experiências, diante do original/tradução beckettiano, não possuem autoridade nenhuma. Essa carência de autoridade não se dá por serem traduções falhadas, mas sim pela grande sombra que a própria ideia de "original" projeta sobre elas. As outras traduçōes da obra de Beckett só teriam condiçôes de circular de fato em um mundo em que o desejo pelo original puro inexistisse, em um certo sentido um mundo em que a mensagem de Ariadna chegasse ao Minotauro. 
Ricardo Pinto de Souza, doutor em Ciência da Literatura pelo Programa de Pós-Graduação em Ciência da Literatura da Universidade Federal do Rio de Janeiro, professor-adjunto de Teoria Literária da Faculdade de Letras da mesma instituição. É coordenador do Laboratório de Edição do PPG em Ciência da Literatura e editor da Revista Terceira Margem. Autor dos livros Culturas (poemas, 2007) e Bestiário (contos, 2008). E-mail: <ricardo.pintodesouza@gmail.com> 